\title{
Prevalence and Associated Factors of Hypertension among Adults living in the City of Bandundu, Republic Democratic Republic of the Congo: A Population-Based Cross-Sectional Study
}

\author{
Ferdinand Mukoso Ngakieb1, Aliocha Nkodila Natuhoyila',33*, François Lepira Bompeka1, \\ Pascal Bayauli ${ }^{4}$, Yves Lubenga', Benjamin Kingama Munsi' ${ }^{5}$, Joseph Shambo Bakali' \\ Tresor Ndongala Nsusu' ${ }^{5}$, Zéphirin Kamuanga1, Oscar Nsu'kier Kolenziame5, \\ Philippe Lukanu Ngwala ${ }^{3}$, Jean René M’Buyamba Kabangu ${ }^{1}$, Benjamin Longo Mbenza ${ }^{1,2}$
}

${ }^{1}$ Department of Cardiology, University of Kinshasa, Kinshasa, Democratic Republic of Congo

${ }^{2}$ Department of Public Health, Lomo University Research, Kinshasa, Democratic Republic of Congo

${ }^{3}$ Department of Family Medicine, Protestant University in Congo, Kinshasa, Democratic Republic of Congo

${ }^{4}$ Department of endocrinology, University of Kinshasa, Kinshasa, Democratic Republic of Congo

${ }^{5}$ Department of Health Sciences, Higher Institute of Medical Techniques of Bandundu, Bandundu, Democratic Republic of Congo Email: *nkodilaaliocha@gmail.com

How to cite this paper: Ngakieb, F.M., Natuhoyila, A.N., Bompeka, F.L., Bayauli, P., Lubenga, Y., Munsi, B.K., Bakali, J.S., Nsusu, T.N., Kamuanga, Z., Kolenziame, O.N., Ngwala, P.L., Kabangu, J.R.M. and Mbenza, B.L. (2021) Prevalence and Associated Factors of Hypertension among Adults living in the City of Bandundu, Republic Democratic Republic of the Congo: A Population-Based Cross-Sectional Study. Open Access Library Journal, 8: e7303 https://doi.org/10.4236/oalib.1107303

Received: March 11, 2021

Accepted: April 23, 2021

Published: April 26, 2021

\begin{abstract}
Background and Aim: In limited resource settings, reliable epidemiological data generated from hypertension high risk geographical areas or people is a prerequisite for the planning of proven and effective interventions. The aim of the present survey was to assess the prevalence, awareness, control and factors associated with hypertension in adults living in the port City of Bandundu, located in the southwestern part of DRC. Methods: a cross-sectional survey using a modified WHO STEPwise questionnaire for data collection during face-to-face interviews were conducted from $1^{\text {st }}$ May to $30^{\text {th }}$ October 2018. A multistage cluster sampling method was used and inclusion criteria were age $\geq 18$ years and informed consent. Information on demographic parameters, behavioral lifestyles, anthropometric and blood pressure (BP) measurements were obtained. Hypertension was defined as an average of two BP $\geq 140 / 90 \mathrm{mmHg}$ or self-reported history of antihypertensive medication use. Independent factors associated with hypertension were identified using logistic regression analysis. Results: The prevalence of hypertension was 34.5\% (Women 36.6\%). Older age $(\mathrm{p}<0.001)$, subclinical atherosclerosis $(\mathrm{p}=$ $0.021)$, sleep duration $<8$ hours $(\mathrm{p}<0.002)$, diabetes mellitus $(\mathrm{p}<0.001)$, and
\end{abstract}


Copyright $\odot 2021$ by author(s) and Open Access Library Inc.

This work is licensed under the Creative Commons Attribution International License (CC BY 4.0).

http://creativecommons.org/licenses/by/4.0/ obesity $(\mathrm{p}=0.009)$ emerged as main cardiovascular risk factors associated with hypertension. Conclusion: Hypertension was characterized by a high prevalence, low rate of awareness and suboptimal BP control, high cardiovascular risk and associated sleep duration and obesity as modifiable risk factors.

\section{Subject Areas}

Cardiology, Public Health

\section{Keywords}

Hypertension, Prevalence, Associated Factors, Black Africans

\section{Introduction}

In sub-Saharan Africa (SSA), hypertension is recognized as the foundation of the epidemics of cardiovascular disease (CVD) [1] and is associated with increased cardiovascular (CV) morbidity and mortality [2]. Factors underlying this high $\mathrm{CV}$ morbidity and mortality include low awareness of hypertension and its complications, under-diagnosis and treatment as well as poor treatment control; all these factors are known to increase the likelihood of developing target organ damage and subsequent overt cardiovascular disease (CVD) [3] [4] Therefore, prevention through increasing awareness, early diagnosis and management of hypertension has been recommended by international guidelines on the diagnosis and management of hypertension as a rationale strategy to mitigate the negative impact of hypertension on the health and socio-economic sectors [5] [6]. The implementation and success of such a strategy imply the availability of information on at risk groups, the burden of the disease in terms of prevalence and associated risk factors, awareness, treatment and control as well as the tracking overtime of hypertension and associated risk factors. Unfortunately, despite growing evidence that the prevalence of hypertension is rising in SSA, reliable nationwide data on this condition that can guide programming are missing for many countries highlighting thus the need to fill in this gap. In this regard, to provide core data on established risk factors, among which hypertension, for the major NCDs within the context of low-resource settings, WHO designed the STEPwise approach to Surveillance (STEPS) [7]. STEPS uses a modular structure with standardized questions and protocols, allowing adjustment of its application and appropriate comparisons of surveys [7]. In addition to launching STEPwise approach, WHO advises limited resource countries to adopt a strategy targeting high CV risk populations or settings, like ports, to mitigate the negative impact of hypertension and associated risk factors [1].

In the Democratic Republic of the Congo (DRC), the nationwide prevalence of hypertension and associated risk factors is not yet available due lack of an effective nationwide surveillance system and financial constraints; however, stu- 
dies conducted in some urban and rural areas have reported a prevalence of hypertension ranging from $30 \%$ to $40 \%$ and an increased CV mortality due, among others, to low awareness, under-diagnosis and under-treatment as well as poor hypertension control [8] [9] [10]. If studies have been conducted in port cities like Kinshasa, Bukavu and Matadi, there are not yet epidemiological data on hypertension and associated risk factors in Bandundu. Therefore, the aim of the present study was to assess the burden of hypertension and associated risk factors among adults living in the City of Bandundu.

\section{Materials and Methods}

This was a population-based cross-sectional study involving adult population randomly selected during period from $1^{\text {st }}$ May to $30^{\text {th }}$ October 2018. The City Bandundu is distant $400 \mathrm{~km}$ from Kinshasa is accessible by road via Mbakana or Mongata on the national 2. The Congo River being navigable in this part located upstream from Kinshasa, also allows access to the city tans by going up the river Kasai to the confluence of Kwilu and Kwango. By plane, the $230 \mathrm{~km}$ which separate the city of Bandundu from Kinshasa are covered in 45 minutes of flight. Study population and sampling

A multistage probability sampling method was used to estimate the sample size which was calculated using the formula: $n \geq\left(Z^{2} \times(p)(1-p)\right) / d^{2} \quad$ [8] where $\mathrm{n}=$ Sample size, $\mathrm{z}=1.96$ (confidence coefficient), $\mathrm{p}=$ previous prevalence, $\mathrm{d}=$ 0.05 (margin of error or range of imprecision reflecting the degree of precision absolute wanted). Because of the probable non-responding subjects, $10 \%$ of the number calculated at the height should be added. We estimated that hypertension reached $50 \%$ of households in the city of Bandundu, as prescribed in the literature, in the absence of a documented prevalence of such disease in the city. The sample size thus calculated was $\mathrm{n} \geq(1.96) 2 \times 0.5 \times 0.5 /(0.05) 2=384$. By adding $10 \%$ of non-respondents, we obtained a size of 422 . We multiplied the sample by 3 because of a population made up of different characteristics. This is what gave a height of 1266 housewives to interview. After questionnaire verification, a total of 1000 eligible people were successfully interviewed among households that gave their informed consent, resulting in a response rate of $79 \%$.

Participants were included in the study if they were aged 18 years and above, living in Bandundu's city more than a year. Non-inclusion criteria included pregnancy.

Data for demographic and behavioral characteristics were obtained by self-reporting during face-to-face interviews. Demographic variables included items on gender, age, and marital status, level of education, employment status, hypertension duration and average monthly income.

The anthropometric measurements (such as body weight, waist circumference, height) blood pressure, and pulse rate were collected by well-trained Medical students. Blood pressure was measured using digital blood pressure measurement devices (OMRON MIT5 Connect, Kyoto, Japan) and recorded 
during household visits following the STEPS methods at the left arm at heart level after a period of 5 minutes of rest). The average of the two measurements was used in the analysis.

Height was measured, while the participants were in an upright position without shoes, by using a flexible tape meter (Hemostyl, Sulzbach, Germany). Body weight was also measured with individuals wearing light clothing or standing without shoes using adigital weighing scale (Deluxe GBS-721; Seca Deutschland, Hamburg, Germany). Body mass index (BMI) was computed as weight in kilograms divided by height in meters squared $\left(\mathrm{Kg} / \mathrm{m}^{2}\right)$. A flexible tape meter was used to measure the waist at the level directly above the iliac crest.

During the household visits, questionnaires on tobacco smoking and chewing, intake of fruit and vegetable and patterns of physical activities were administered. Participants were asked about their fruits and vegetables consumption in a typical week, number of days and the number of servings on those days was collected. Fruits and vegetable consumption was analyzed as number of times per week. The Global Physical Activity Questionnaire Version 2 was used to collect the information on physical activities [9] [10] [11].

\subsection{Operational Definitions}

Hypertension was defined as either having a $\mathrm{BP} \geq 140 / 90 \mathrm{mmHg}$ and/or self-report of previous diagnosis of hypertension by a health care provider and/or if currently taking antihypertensive drug. Awareness as self-report of prior diagnosis by a health care provider among the participants with hypertension. Treatment of hypertension as using pharmacologic blood lowering medicines at the time of the interview among those aware of their hypertensive status. BP control BP $<140 \mathrm{mmHg}$ while on treatment among those on treatment; isolated systolic, isolated and systolic-diastolic uncontrolled BP in treated patients were defined as SBP $\geq 140 \mathrm{mmHg}$ and DBP $<90 \mathrm{mmHg}, \mathrm{SBP}<140 \mathrm{mmHg}$ and DBP $\geq 90$ $\mathrm{mmHg}$ and $\mathrm{SBP} \geq 140 \mathrm{mmHg}$ and $\mathrm{DBP} \geq 90 \mathrm{mmHg}$, respectively [12].

Diabetes was defined as fasting capillary blood glucose, $110 \mathrm{mg} / \mathrm{dl}$ or history of antidiabetic treatment [13].

Low fruit/vegetable consumption of less than 5 portions of fresh and/or cooked fruits/vegetables a day [14]. The Global Physical Activity Questionnaire was used to collect information on physical activity. Insufficient physical activity was defined as self-reported less than 150 min of moderate intensive activity or less than 75 min vigorous intensive physical activity per week, including walking and cycling [11].

Body Mass Index (BMI): computed from the height and weight of the respondent-weight divided by height squared $\left(\mathrm{Kg} / \mathrm{m}^{2}\right)$. The BMI was further classified into four categories; underweight (BMI $<18.5 \mathrm{Kg} / \mathrm{m}^{2}$ ), normal (BMI 18.5 $24.99 \mathrm{Kg} / \mathrm{m}^{2}$ ), overweight (BMI $25-29.99 \mathrm{Kg} / \mathrm{m}^{2}$ ) and obese $\left(B M I \geq 30 \mathrm{Kg} / \mathrm{m}^{2}\right.$ [15]. Waist circumference (WC) was used as surrogate for abdominal obesity, defined as a WC value $>94 \mathrm{~cm}$ in men and $>80 \mathrm{~cm}$ in women [16]. High cardi- 
ometabolic risk (CMR) as the waist-to-height ratio $\geq 0.5$ [17].

Harmful use of alcohol was defined as consumption of more than 1 standard drink (which is the amount of alcohol you find in a small beer, one glass of wine, or one tot of spirits per day for females and more than 2 standard drinks for males [18]. Smoking was defined as current use of smoked or smokeless tobacco [19]. According to 2013-2014 DRC Demographic and Health Survey (DHS), low, middle and high socioeconomic status (SES) scores were defined as 0 - 3, 4 - 8 and $>9$ respectively [20]. The cut of the old age is $>60$ years and the High sugar diet is the consumption of sweet substance more than 5 times a day.

\subsection{Statistical Analyzes}

Data were presented as the mean and standard deviation for the normally distributed continuous variables. The absolute and relative frequencies were used to illustrate the qualitative variables. The student's t test was used to compare group means. However, we used Pearson's chi-square or Fischer's exact test to compare the proportions. The factors associated with arterial hypertension were sought using a logistic regression test with calculation of the odds ratio and their confidence intervals finally to estimate the degree of association. $\mathrm{p}<0.05$ was the significance level statistical. Analyzes were performed using SPSS for Windows version 21 software.

\subsection{Ethical Approval}

This research was conducted in strict compliance with the recommendations of the Helsinki Declaration III. The three principles of research ethics were respected, namely: respect for the human person, beneficence and justice. Respect for the human person was ensured by the anonymity system enshrined in the data collection sheets where the name was replaced by a code known only to the investigator (confidentiality required); beneficence was assured by the absence of morbidity associated with this study. Respect for justice was guaranteed by the free consent of the respondents to participate in the study and the right of the latter to withdraw from it at any time. All participants were informed of the objectives of the study, the conditions for participation and the procedure for clinical and para-clinical examinations. The research protocol for this study was submitted and presented to the medical ethics committee of the School of Public Health of University of Kinshasa and whose approval number is referenced $\mathrm{ESP} / \mathrm{CE} / 054 / 2018$.

\section{Results}

\subsection{General Characteristics of the Study Population}

In total, 1000 respondents were included in this study, including 628 women (ie $62.8 \%$ ) and 372 men (ie $37.2 \%$ ). The sex ratio of $2 \mathrm{~F} / 1 \mathrm{H}$. Respondents aged under 40 were in the majority (34.9\%); respondents without a profession were more represented (39.7\%). The married were predominant (70.1\%); Respondents with 
secondary education (51.1\%) and those attending revival church (40.0\%) were more numerous; more than half of this population had a low socioeconomic level $(61.4 \%)$.

\subsection{Prevalence and Clinical Profile of Hypertension}

Of the total number of respondents who participated in the study, 345 people had $\mathrm{BP} \geq 140 / 90 \mathrm{mmHg}$ or were receiving an antihypertensive drug, i.e. an overall prevalence of hypertension of $34.5 \%$ (i.e. $30.9 \%$ in men and $36.6 \%$ in women, $\mathrm{p}=0.065)$ (Figure 1).

The FRCVs most frequently associated with hypertension were HF-DS $(14.8 \%, \mathrm{p}=0.001)$, HF-MCV $(4.6 \%, \mathrm{p}=0.007)$, tobacco $(27 \%, \mathrm{p}=0.002)$, sedentary lifestyle $(33 \%, \mathrm{p}<0.001)$, gout $(3.5 \%, \mathrm{p}=0.009)$, menopause $(41.2 \%, \mathrm{p}<$ $0.001)$, ATS (40.6\%, p < 0.001), overweight (24.6\%, p = 0.001), obesity $(15.7 \%, \mathrm{p}$ $=0.001)$, abdominal obesity $(50.7 \%, \mathrm{p}<0.001), \operatorname{MCR}(25.8 \%, \mathrm{p}<0.001), \mathrm{SD}$ $(23.1 \%, \mathrm{p}<0.001)$ and sleep duration $<8$ hours $(44 \%, \mathrm{p}=0.005)$ (Table 1$)$.

\subsection{Factors Associated with Hypertension}

In univariate analysis, advanced age, smoking, sedentary lifestyle, gout, menopause, sleep duration $<8$ hours, ATS, overweight, obesity, abdominal obesity and diabetes mellitus had emerged as the main determinants of hypertension.

In multivariate analysis, the strength of association observed in univariate analysis persisted only for age, sleep duration $<8$ hours, Subclinical atherosclerosis, obesity and diabetes mellitus having emerged as the main major determinants of hypertension. The risk was multiplied by 3 in the elderly (adjusted OR $5.8795 \%$ CI [3.04 - 11.36], p $=0.000)$, by 7 in females aged 45 years and over (OR: 2.98 95\% CI: $(2.05-4.35), \mathrm{p}<0.001)$, by 2 for sleep duration $<8$ hours (adjusted OR 1.96 95\% CI: $(1.28$ - 3.01), $\mathrm{p}=0.002)$, by 9 for Subclinical atherosclerosis (adjusted OR 8.90 95\% CI: (5.65 - 14.02), p < 0.001), by 3 for obesity (adjusted OR 2.68, 95\% CI: (1.92 - 3.17), p = 009) and by 2 for diabetes mellitus (adjusted OR 2.34, 95\% CI: (1.47 - 3.71), p < 0.001) (Table 2).

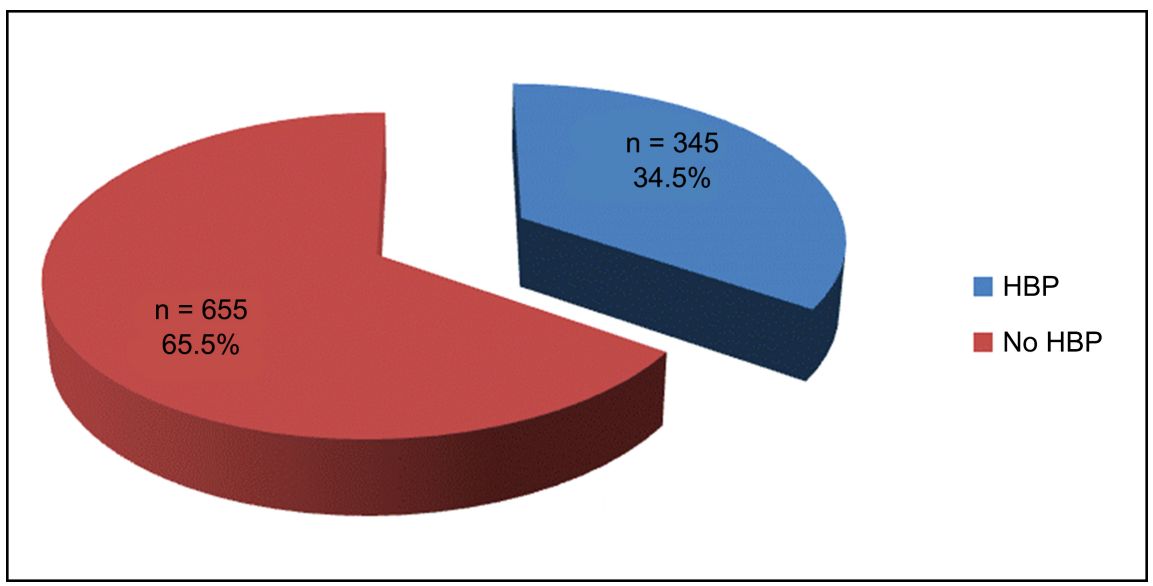

Figure 1. Overall prevalence of hypertension in the study population. 
Table 1. Clinical characteristics of the study population as a whole and by hypertension status.

\begin{tabular}{|c|c|c|c|}
\hline FRCV & $\begin{array}{c}\text { HBP } \\
\mathrm{n}=345\end{array}$ & $\begin{array}{c}\text { No HBP } \\
\mathrm{n}=655\end{array}$ & $\mathrm{p}$ \\
\hline Old age, n (\%) & $237(68.7)$ & $208(31.8)$ & $<0.001$ \\
\hline FH-HT, n (\%) & $88(25.5)$ & $167(25.5)$ & 0.527 \\
\hline FH-DM, n (\%) & $51(14.8)$ & $52(7.9)$ & 0.001 \\
\hline FH-Obésité, n (\%) & $9(2.6)$ & $20(3.1)$ & 0.428 \\
\hline FH-CVD, n (\%) & $16(4.6)$ & $11(1.7)$ & 0.007 \\
\hline FH-RCD, n (\%) & $4(1.2)$ & $5(0.8)$ & 0.378 \\
\hline FH-Dyslipidémia, n (\%) & $4(1.2)$ & $11(1.7)$ & 0.712 \\
\hline Tabacco, n (\%) & $93(27.0)$ & $122(18.6)$ & 0.002 \\
\hline Alcohol, n (\%) & $113(32.8)$ & $200(30.5)$ & 0.258 \\
\hline Sedentarity, n (\%) & $114(33.0)$ & $137(20.9)$ & $<0.001$ \\
\hline Gout, $\mathrm{n}(\%)$ & $12(3.5)$ & $7(1.1)$ & 0.009 \\
\hline Menopause, n (\%) & $142(41.2)$ & $108(16.5)$ & $<0.001$ \\
\hline Stroke, n (\%) & $8(2.3)$ & $0(0.0)$ & - \\
\hline Heart disease, $\mathrm{n}(\%)$ & $13(3.8)$ & $0(0.0)$ & - \\
\hline Subclinical Athérosclerosis, $\mathrm{n}(\%)$ & $140(40.6)$ & $32(4.9)$ & $<0.001$ \\
\hline Tachycardia, n (\%) & $34(9.9)$ & $81(12.4)$ & 0.140 \\
\hline Overweight, n (\%) & $85(24.6)$ & $106(16.2)$ & 0.001 \\
\hline Obesity, n (\%) & $54(15.7)$ & $56(8.5)$ & 0.001 \\
\hline Abdominal Obesity, n (\%) & $175(50.7)$ & $205(31.3)$ & $<0.001$ \\
\hline CMR, n (\%) & $89(25.8)$ & $94(14.4)$ & $<0.001$ \\
\hline $\mathrm{DM}, \mathrm{n}(\%)$ & $68(23.1)$ & $58(11.5)$ & $<0.001$ \\
\hline Sleep duration, $\mathrm{n}(\%)$ & & & 0.005 \\
\hline$<8$ hours & $148(44.0)$ & $215(33.8)$ & \\
\hline 8 hours & $118(35.1)$ & $250(39.3)$ & \\
\hline$>8$ hours & $70(20.8)$ & $171(26.9)$ & \\
\hline Physical activity, n (\%) & & & 0.221 \\
\hline Inactive & $196(56.8)$ & $354(54.0)$ & \\
\hline Active & $194(43.2)$ & $301(46.0)$ & \\
\hline Diet rich in animal fat, $\mathrm{n}(\%)$ & $132(38.3)$ & $247(37.7)$ & 0.459 \\
\hline Diet rich in vegetable fat, $\mathrm{n}(\%)$ & $54(15.7)$ & $102(15.6)$ & 0.521 \\
\hline Diet rich in fruit and vegetable, $\mathrm{n}(\%)$ & $287(83.2)$ & $511(78.0)$ & 0.131 \\
\hline High sugar diet, n (\%) & $63(18.3)$ & $120(18.3)$ & 0.527 \\
\hline
\end{tabular}

Data are expressed as absolute ( $\mathrm{n}$ ) and relative (in percent) frequency. Abbreviations: $\mathrm{M}$, male F, female FH, family history HT, hypertension DM, diabetes mellitus CVD, cardiovascular disease PH, personal history, CMR, cardiometabolic risk. 
Table 2. Cardiovascular risk factors associated with hypertension in multivariate analysis.

\begin{tabular}{|c|c|c|c|c|}
\hline \multirow{2}{*}{ Variables } & \multicolumn{2}{|c|}{ Univariate analysis } & \multicolumn{2}{|c|}{ Multivariate analysis } \\
\hline & $\mathrm{p}$ & OR $(95 \% \mathrm{CI})$ & $\mathrm{p}$ & Adjusted OR (95\%CI) \\
\hline \multicolumn{5}{|l|}{ Old age } \\
\hline No & & 1 & & 1 \\
\hline Yes & $<0.001$ & $4.72(3.56-6.25)$ & $<0.001$ & $2.98(2.05-4.35)$ \\
\hline \multicolumn{5}{|l|}{ Tabacco } \\
\hline No & & 1 & & 1 \\
\hline Yes & 0.002 & $1.61(1.18-2.20)$ & 0.153 & $1.34(0.90-1.99)$ \\
\hline \multicolumn{5}{|l|}{ Sedentarity } \\
\hline No & & 1 & & 1 \\
\hline Yes & $<0.001$ & $1.87(1.39-2.50)$ & 0.121 & $1.36(0.92-1.99)$ \\
\hline \multicolumn{5}{|l|}{ Gout } \\
\hline No & & 1 & & 1 \\
\hline Yes & 0.012 & $3.34(1.30-8.55)$ & 0.604 & $1.35(0.44-4.15)$ \\
\hline \multicolumn{5}{|l|}{ Menopause } \\
\hline No & & 1 & & 1 \\
\hline Yes & $<0.001$ & $3.54(2.64-4.77)$ & 0.145 & $1.36(0.90-2.05)$ \\
\hline \multicolumn{5}{|l|}{ Sleep duration } \\
\hline 8 hours & & 1 & & 1 \\
\hline$>8$ hours & 0.115 & $1.46(0.18-1.97)$ & 0.069 & $1.40(0.97-2.02)$ \\
\hline$<8$ hours & 0.003 & $1.68(1.19-2.38)$ & 0.002 & $1.96(1.28-3.01)$ \\
\hline \multicolumn{5}{|c|}{ Subclinic atherosclerosis } \\
\hline No & & 1 & & 1 \\
\hline Yes & $<0.001$ & $13.30(8.77-20.14)$ & $<0.001$ & $8.90(5.65-14.02)$ \\
\hline \multicolumn{5}{|l|}{ Overweight } \\
\hline No & & 1 & & 1 \\
\hline Yes & 0.001 & $1.69(1.23-2.34)$ & 0.096 & $1.90(0.17-3.06)$ \\
\hline \multicolumn{5}{|l|}{ Obesity } \\
\hline No & & 1 & & 1 \\
\hline Yes & 0.001 & $1.99(1.33-2.96)$ & 0.009 & $2.68(1.92-3.17)$ \\
\hline \multicolumn{5}{|l|}{ Abdominal obesity } \\
\hline Non & & 1 & & 1 \\
\hline Oui & $<0.001$ & $2.26(1.73-2.95)$ & 0.203 & $1.33(0.86-2.07)$ \\
\hline \multicolumn{5}{|l|}{ Diabete mellitus } \\
\hline No & & 1 & & 1 \\
\hline Yes & $<0.001$ & $2.53(1.73-3.69)$ & $<0.001$ & $2.34(1.47-3.71)$ \\
\hline
\end{tabular}




\section{Discussion}

The main findings of the present study are as follows. First, nearly 4 out of 10 participants, mainly women had hypertension. Second, the proportion of participants aware, treated and controlled was low in the present study. Third, despite high global cardiovascular risk, the majority of treated participants were receiving monotherapy with mainly calcium channel blockers. Fifth, older age sleep duration $<8 \mathrm{~h}$, Subclinical atherosclerosis, diabete mellitus and obesity as modifiable risk factors were independent factors associated with hypertension.

Nearly 4 out of 10 participants, mainly women had hypertension in the present study. Our finding agrees with previous studies from the Democratic Republic of the Congo reporting increased prevalence of hypertension in urban and rural settings [9] [10]. It is also consistent with findings of increased prevalence of hypertension from Central [21] [22], Eastern [23] [24], Southern [25] [26] and Western [27] [28] [29] [30] [31] sub-Saharan African countries. Differences in study populations, sample size and methodology used as well as in geographical distribution of traditional and emerging cardiovascular risk factors could explain the observed disparities in hypertension prevalence between studies. The level and speed of the epidemiological transition between sub-Saharan African countries could also contribute to these disparities [32]. Hypertension was more frequent in women than men in the present study. Our finding contrasts with that of previous studies from the Democratic Republic of the Congo [9] [10] [33] who reported a higher prevalence of hypertension in men than women. However, it is consistent with that of studies from other sub-Saharan Africa countries [34] [35]. The high prevalence of hypertension in women in the present study could be probably due to the inclusion of more women than men. The menopause with subsequent loss of estrogen-afforded cardiovascular protection could be an explanatory factor for the increased prevalence of hypertension in women [36] [37]; however, the mean age of the study population (36 years) does not allow to ascertain this hypothesis.

Older age and Subclinical atherosclerosis as non-modifiable and sleep duration $<8 \mathrm{~h}$, diabete millitus and obesity as modifiable risk factors were independent factors associated with hypertension. Older age has been reported to be one of the most powerful cardiovascular risk factors through oxidative stress-induced endothelial dysfunction [38] and subsequent vascular remodeling as well as the coexistence of multiple cardiovascular risk factors via insulin resistance [39]. The association of Subclinical atherosclerosis and hypertension does translate the existence of a potential genetic susceptibility that does interact with environmental factors for the development and progression of hypertension and related end-organ damage. In this regard, studies from African Americans (AA) have reported that young AA adults bearing apolipoprotein L1 (APOL1) gene variants, well-known renal-risk factors in people of African descent, manifested elevated systolic blood pressure (SBP) prior to glomerular filtration rate (GFR) 
decline and earlier hypertension suggesting that APOL1 variants affect initially vascular cells. Thus, APOL1 genetic testing can identify young individuals of African ancestry with increased BP burden and risk of hypertension related end-organ damage [40]. A recent study by Sumaili et al. from the University of Kinshasa Hospital has reported an association between APOL1 gene renal-risk variants and blood pressure among patients with hypertension-related kidney disease [41] [42] and diabete mellitus/obesity are well-known traditional risk factors sharing insulin resistance, sympathetic nervous (SNS) and renin angiotensin aldosterone (RAAS) systems, oxidative stress and subsequent inflammation and endothelial dysfunction as a common pathogenic pathway for cardiac and vascular damage [43].

The interpretation of the results of the present survey should take into account of some limitations. First, the cross-sectional design of the survey precludes the establishment of any temporal relationship between the outcome and the variables of interest. Second, the unique measurement of the variables of interest could have under- or overestimated their true values and the prevalence of hypertension and associated risk factors. Third, other factors usually associated with hypertension such as blood lipids were not measured.

\section{Conclusion}

The present survey showed that nearly four participants out of ten had hypertension that was associated with older age, Subclinical atherosclerosis, sleep duration, diabetes mellitus and obesity as main cardiovascular risk factors. A management strategy based on both therapeutic lifestyle changes (TLC) and pharmacological treatment is needed for those hypertensive participants with increased global cardiovascular risk.

\section{Acknowledgements}

The authors would like to express their deepest gratitude to the Administrative Authorities of Bandundu City and the Academic Staff of the University of Bandundu for their invaluable assistance. We are deeply indebted to all the participants who make this survey possible through their informed consent. We would like to particularly thank all the fieldworkers for their commitment for the success of the present survey.

\section{Authors' Contributions}

Ferdinand Mukoso Ngakieb, Aliocha Nkodila Natuhoyila and Francois LepiraBompeka designed and analyzed the statistical data for the study. Benjamin Kingama Munsi, Joseph Shambo Bakali, Tresor Ndongala Nsusu, Zéphirin Kamuanga, Oscar Nsu'kier Kolenziame, contributed to the data collection. Yves Lubenga, Philippe Lukanu Ngwala, Pascal Bayauli, Jean René M’Buyambaand Benjamin Longo Mbenza supervised the study. All authors have read and approved the final and revised version of the manuscript. 


\section{Conflicts of Interest}

The authors declare no conflicts of interest regarding the publication of this paper.

\section{References}

[1] Cooper, R.S., Amoah, A.G. and Mensah, G.A. (2003) High Blood Pressure: The Foundation for Epidemic Cardiovascular Disease in African Populations. Ethnicity \& Disease, 13, S48-S52.

[2] Kearney, P.M., Whelton, M., Reynolds, K., Muntner, P., Whelton, P.K. and He, J. (2005) Global Burden of Hypertension: Analysis of Worldwide Data. The Lancet, 365, 217-223. https://doi.org/10.1016/S0140-6736(05)17741-1

[3] Ataklte, F., Erqou, S., Kaptoge, S., Taye, B., Echouffo-Tcheugui, J.B. and Kengne, A.P. (2015) Burden of Undiagnosed Hypertension in Sub-Saharan Africa Novelty and Significance: A Systematic Review and Meta-Analysis. Hypertension, 65, 291-298. https://doi.org/10.1161/HYPERTENSIONAHA.114.04394

[4] Ibrahim, M.M. and Damasceno, A. (2012) Hypertension in Developing Countries. The Lancet, 380, 611-619. https://doi.org/10.1016/S0140-6736(12)60861-7

[5] Williams, B., Mancia, G., Spiering, W., et al. (2018) Guidelines for the Management of Arterial Hypertension. European Heart Journal, 39, 3021-3104.

https://doi.org/10.1093/eurheartj/ehy339

[6] Nicole Abel, N., Krysta, C.K., Navjot, J.N., Navjot, G., Elizabeth, G., Iris, H., et al. (2015) Eighth Joint National Committee (JNC-8) Guidelines and the Outpatient Management of Hypertension in the African-American Population. North American Journal of Medical Sciences, 7, 438-445.

https://doi.org/10.4103/1947-2714.168669

[7] World Health Organization (2016) The STEPS Instrument and Support Materials. http://www.who.int/chp/steps/instrument/en

[8] Giezendanner, F.D. (2012) Taille d'un échantillon aléatoire et Marge d'erreur. CMS-SPIP. http://icp.ge.ch/sem/cms-spip/spip.php?article1641

[9] World Health Organization (2009) Global Physical Activity Questionnaire (GPAQ): Nine Country Reliability and Validity Study. Journal of Physical Activity \& Health, 6, 790-804. https://doi.org/10.1123/jpah.6.6.790

[10] Katchunga, P.B., Mirindi, P., Baleke, P., Ntaburhe, T., Twagirumukiza, M. and M'Buyamba-Kabangu, J.R. (2019) The Trend in Blood Pressure and Hypertension Prevalence in the General Population of South Kivu between 2012 and 2016: Results from Two Representative Cross-Sectional Surveys-The Bukavu Observational Study. PLoS ONE, 14, e0219377. https://doi.org/10.1371/journal.pone.0219377

[11] Kianu, B., Mpembele, E., Kintoki, E.V., Makulo, J.R., Kiazayawoko, F.Z., Manyebwa, K.J.D.D., et al. (2015) Rates of Hypertension Prevalence, Awareness, Treatment, and Control in Congolese South West Port City. The Influence of Gender According to Groups. Global Journal of Medical Research, 15, 1-8.

[12] Neo, M.T., Lei, C., Gontse, T., Moagi, G., Tebogo, M., et al. (2020) Prevalence and Determinants of Hypertension Awareness, Treatment, and Control in Botswana: A Nationally Representative Population-Based Survey. International Journal of Hypertension, 41, 1-12.

[13] Expert Committee on the Diagnosis and Classification of Diabetes Mellitus (2003) Report of the Expert Committee on the Diagnosis and Classification of Diabetes Mellitus. Diabetes Care, 26, S5-S20. https://doi.org/10.2337/diacare.26.2007.S5 
[14] Gadallah, M., Abdel, S., Mohsen, A. and Kandil, S. (2018) Hypertension and Associated Cardiovascular Risk Factors among Urban Slum Dwellers in Egypt: A Population-Based Survey. Eastern Mediterranean Health Journal, 24, 435-442. https://doi.org/10.26719/2018.24.5.435

[15] World Health Organization (WHO) (2000) The Problem of Overweight and Obesity: Preventing and Managing the Global Epidemic. Report Series 894, WHO, Geneva, 537.

[16] Alberti, K.G., Zimmet, P. and Shaw (2006) Metabolic Syndrome-A New World-Wide Definition. A Consensus Statement from the International Diabetes Federation. Diabetic Medicine, 5, 469-480. https://doi.org/10.1111/j.1464-5491.2006.01858.x

[17] Browning, L., Hsieh, S. and Ashwell, M. (2010) A Systematic Review of Waist-to-Height Ratio as a Screening Tool for the Prediction of Cardiovascular Disease and Diabetes: 0.5 Could Be a Suitable Global Boundary Value. Nutrition Research Reviews, 23, 247-269. https://doi.org/10.1017/S0954422410000144

[18] Takeshi, K., laria, P., Maufroy, N., Jean Philippe, D., Isabelle, M., Fakher, N., et al. (2006) Arterial Hypertension and Arterial Pulse. MT Cardio, 2, 493-501.

[19] Orth, S.R., Stockmann, A., Conradt, C., Ritz, E., Ferro, M., Kreusser, W., et al. (2008) Smoking as a Risk Factor for End-Stage Renal Failure in Men with Primary Renal Disease. Kidney International, 54, 926-931. https://doi.org/10.1046/j.1523-1755.1998.00067.x

[20] Ministry of Heath and Ministry of Planification, Preliminary (2014) 2013-2014 Democratic Republic of the Congo Demographic and Health Survey (DHS).

[21] Nansseu, J.R., Kameni, B.S., Assah, F.K., Bigna, J.J., Petnga, S.J., et al. (2019) Prevalence of Major Cardiovascular Disease Risk Factors among a Group of Sub-Saharan African Young Adults: A Population-Based Cross-Sectional Study in Yaoundé, Cameroon. BMJ Open, 9, e029858. https://doi.org/10.1136/bmjopen-2019-029858

[22] Kimbally, E., Gombet, T., Bolanda, J.D., Woumbo, Y., Okili, B., Ellenga, M.B., et al. (2006) Prevalence of Hypertension artérielle in Brazzaville. Cardiologie Tropicale, 32: 43-46.

[23] Nuwaha, F. and Musinguzi, G. (2013) Pre-Hypertension in Uganda: A Cross-Sectional Study. BMC Cardiovascular Disorders, 13, Article No. 101. https://doi.org/10.1186/1471-2261-13-101

[24] Irazola, E.Z. (2016) Hypertension Prevalence, Awareness, Treatment, and Control in Selected Communities of Nine Low- and Middle-Income Countries: Results from the NHLBI/UHG Network of Centers of Excellence for Chronic Diseases. Global Heart, 11, 47-59. https://doi.org/10.1016/j.gheart.2015.12.008

[25] Pedro, J.M., Brito, M. and Barros, H. (2018) Prevalence, Awareness, Treatment, and Control of Hypertension, Diabetes and Hypercholesterolemia among Adults in Dande Municipality, Angola. Cardiovascular Journal of Africa, 29, 73-81. https://doi.org/10.5830/CVJA-2017-047

[26] Damasceno, A., Azevedo, A., Silva, M.C., Prista, A., Diogo, D. and Lunet, N. (2009) Hypertension Prevalence, Awareness, Treatment and Control in Mozambique. Journal of the American Heart Association, 54, 77-83. https://doi.org/10.1161/HYPERTENSIONAHA.109.132423

[27] Owiredu, E.W., Dontoh, E., Essuman, S.E.S. and Bazanfara, B.B. (2019) Demographic and Lifestyle Predictors of Prehypertension: A Cross-Sectional Study among Apparently Healthy Adults in Kumasi, Ghana. BioMed Research 
International, 2019, Article ID: 1764079. https://doi.org/10.1155/2019/1764079

[28] Guwatudde, D., Nankya-Mutyoba, J., Kalyesubula, R., Laurence, C., Adebamowo, C. and Ajayi, I.O. (2015) The Burden of Hypertension in Sub-Saharan Africa: A Four-Country Cross Sectional Study. BMC Public Health, 15, 1211. https://doi.org/10.1186/s12889-015-2546-Z

[29] Hendricks, M.E., Wit, F.W., Brewster, L.M. and Akande, T.M. (2012) Hypertension in Sub-Saharan Africa: Cross-Sectional Surveys in Four Rural and Urban Communities. PLOS ONE, 7, 32638-32648.

https://doi.org/10.1371/journal.pone.0032638

[30] Balde, M., Blade, N.M., Kaba, M.L., Diallo, I., Diallo, M.M., Kake, A., et al. (2006) Hypertension: Epidemiology and Metabolic Abnormalities in Foutah-Djallon in Guinea. Le Mali Medical, 21, 19-22.

[31] Seck, S.M., Ndiaye, A., Thiam, I. and Gueye, L. (2014) Prevalence of Hypertension and Its Impact on Health's Perception of Rural Populations: Cross-Sectional Study in the Northern Region of Senegal. CVJA, 1, 627-634.

https://doi.org/10.13070/rs.fr.1.627

[32] Steyn, N.P. and Mchiza, Z.J. (2014) Obesity and the Nutrition Transition in Sub-Saharan Africa. Annals of the New York Academy of Sciences, 1311, 88-101. https://doi.org/10.1111/nyas.12433

[33] M’Buyamba-Kabangu, J.R., Fagard, R., Lijnen, P., Staessen, J. and Ditu, M.S. (1986) Epidemiological Study of Blood Pressure and Hypertension in a Sample of Urban Bantu of Zaïre. Journal of Hypertension, 4, 485-491.

https://doi.org/10.1097/00004872-198608000-00015

[34] Ifeoma Ulasi, I.I., Ijoma, C.K., Onyumbere, B.J.C., Arodiwe, E. and Onodugo, O. (2011) High Prevalence and Low Awareness of Hypertension in a Market Population in Enugu, Nigeria. International Journal of Hypertension, 26, 34-39.

https://doi.org/10.4061/2011/869675

[35] Odugbemi, T.O., Onajole, A.T. and Osibogun, A.O. (2012) Prevalence of Cardiovascular Risk Factors among Traders in an Urban Market in Lagos, Nigeria. Nigerian Postgraduate Medical Journal, 19, 1-6.

[36] El Bakkay, S. and Bour, A. (2016) Obesity and Hypertension among Childbearing Women in Morocco. Anthropo, 36, 57-66. (In French)

[37] Cherif, A. and Bouafia, M. (2016) Hypertension Characteristics among Postmenopausal Women at the District of Blida. Annales de Cardiologie et d' ngéiologie, 65, 146-151. (In French)

[38] Plante, G.E. (2003) Impact of Aging on the Body's Vascular System. Metabolism, 52, 31-35. https://doi.org/10.1016/S0026-0495(03)00299-3

[39] Ramos, R., Marrugat, J., Basagaña, X., Sala, J., Masiá, R. and Elosua, R. (2004) The Role of Age in Cardiovascular Risk Factor Clustering in Non-Diabetic Population Free of Coronary Heart Disease. European Journal of Epidemiology, 19, 299-304. https://doi.org/10.1023/B:EJEP.0000024697.55346.c2

[40] Nadkarni, G.N., Galarneau, G., Ellis, S.B., Nadukuru, R., Zhang, J., Scott, S.A., et al. (2017) Apolipoprotein L1 Variants and Blood Pressure Traits in African Americans. Journal of the American College of Cardiology, 69, 1564-1574.

https://doi.org/10.1016/j.jacc.2017.01.040

[41] Sumaili, E.K., Shemer, R., Kruzel-Davila, E., Cohen, E.P., Mutantu, P.N., Bukabau, J.B., et al. (2018) G1 Is the Major APOL 1 Risk Allele for Hypertension-Attributed Nephropathy in Central Africa. Clinical Kidney Journal, 12, 188-195. https://doi.org/10.1093/ckj/sfy073 
[42] Virdis, A., Giannarelli, C., Neves, M.F., Taddei, S. and Ghiadoni, L. (2010) Cigarette Smoking and Hypertension. Current Pharmaceutical Design, 16, 2518-2525. https://doi.org/10.2174/138161210792062920

[43] Reaven, G.M., Lithell, H. and Landsberg, L. (1996) Hypertension and Associated Metabolic Abnormalities-The Role of Insulin Resistance and the Sympathoadrenal System. The New England Journal of Medicine, 334, 374-381.

https://doi.org/10.1056/NEJM199602083340607 